\title{
(Dis)Inclination of Iraqi Medical Students Towards Creative Thinking: A Quasi-Experimental Study
}

\author{
Nawfal Al-Hadithi ${ }^{1} \&$ Ahmed Al-Imam ${ }^{1,2}$ \\ ${ }^{1}$ Department of Anatomy and Cellular Biology, College of Medicine, University of Baghdad, Iraq \\ ${ }^{2}$ Department of Postgraduate Medicine, School of Life and Medical Sciences, University of Hertfordshire, United \\ Kingdom \\ Correspondence: Dr Ahmed Al-Imam, House 18/5, Al-Akhtal Street, District 318, Al-Adhamyia, 10053, Baghdad, \\ Iraq. E-mail: tesla1452@gmail.com; a.m.al-imam@herts.ac.uk
}

Received: July 25, 2017 Accepted: August 17, 2017 Online Published: September 18, 2017

doi:10.5539/gjhs.v9n11p186 URL: https://doi.org/10.5539/gjhs.v9n11p186

\begin{abstract}
Background: There have been several attempts in the past centuries to quantify the human intelligence, many of these attempts were successful. On the other hand, there have been parallel trials to identify and quantify an individual's creativity. To date, there is no universal definition of creativity nor a quantifying system to measure it with a reliable accuracy.
\end{abstract}

Materials and Methods: This is a quasi-experimental study in an Iraqi population of undergraduate medical students aged 18-20 years; the male-to-female ratio is 3 to 10 . The total number of participants was $195(\mathrm{n}=195)$ who were allocated into three groups; $A, B$, and $C\left(n_{A}=67, n_{B}=61, n_{C}=67\right)$. Each group was interviewed separately, and the participants were given a choice to either correspond to a quiz on an already taught medical subject or write down ideas (one or more) with creative-innovative potentials. There was no restriction on time, language, or the theme of the topics to be written.

Results: There was a significant difference in between the three groups' tendency to take the quiz ( $p$-value $=0.040$ ). However, inter-group and intra-group analyses failed to detect any significant difference in students' tendencies towards either a creative or a classical form of thinking. Besides, gender was not found to be of a determinant effect on an individual's tendency towards creativity $(\mathrm{p}=0.633)$ or traditional thinking based on an already taught medical knowledge (0.905).

Conclusion: There were no statistically significant differences in the tendencies of students towards either an original (creative) or a standard pattern of thinking. However, inter-group analyses indicated some substantial differences in students' affinity towards exploring an already taught medical knowledge.

Keywords: Creativity, Creativeness, Creative Thinking, Creative Ability, Innovation, Students, Medical Students, Quasi-Experiment, Chi-Square Test

\section{Background}

The human intellect has always been under relentless investigative efforts to explore the way by which it can solve problems, investigate new patterns, and innovate new concepts. Creativity can be highly versatile; it can be artistic (Figure 1), musical, linguistic, mathematical, athletic, philosophical, applied, etc. Despite that the creative thinking has been studied for centuries, there is no precise definition for what creativity stands for, and to date, there is no reliable unanimous metric system to quantify creativity or the affinity of an individual towards creative thinking (Bailey, 1957; Guertin et al., 1966; Oscoz-Irurozqui \& Ortuño, 2016). 


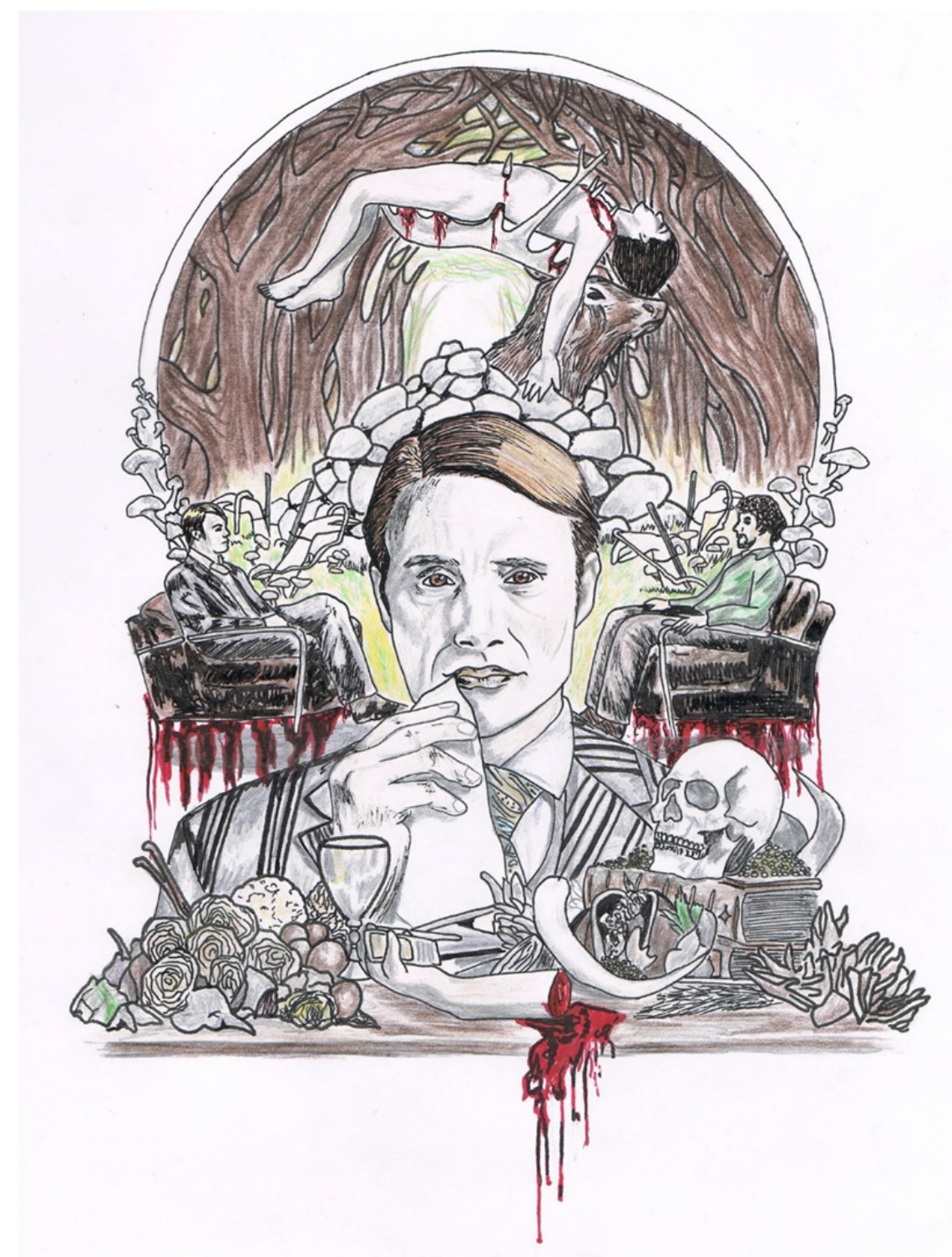

Figure 1. Artistic Creativity: A Concept Art by Hussein Al-Bayati.

For centuries, there have been numerous studies on human intelligence and its measurement, the Intellectual Quotient (IQ); these studies have managed to extrapolate an excellent estimation of an individual's intelligence, for example, the use of Wechsler's scale to measure the IQ (Bayley, 1957; Guertin et al., 1962; Guertin et al., 1966; Seashore et al., 1950). There have also been similar attempts to quantify the creativity and the creative potential of an individual in a similar sense, using the an analogous quotient known as the Creativity Quotient (CQ) (Bossomaier et al., 2009; Furnham et al., 2008; Romey, 1960; Piffer, 2012; Snyder et al., 2005). However, none of these attempts seems to be successful although there have been some promising studies focusing on alternative modalities to assess creativity, including cerebral and cranial morphometry (Bendetowicz et al., 2016), the neural correlates of creativity (Amir, 2016), functional MRI imaging (fMRI) and the assessment of divergent thinking potentials (Kleibeuker et al., 2016), and other studies (Allen and Loughnane, 2016; Amir \& Biederman, 2016; Bendetowicz et al., 2016; Kleibeuker et al., 2016; Oscoz-Irurozqui \& Ortuño, 2016).

This study is quasi-experimental; it exploits the use of a straightforward approach to identify tendencies towards two patterns of thinking, either creative thinking or traditional thinking. This study was authorised by the ethical committee and the institutional review board (IRB) of the College of Medicine at the University of Baghdad. The level of evidence of this paper is estimated to be of level-3 in accordance with the categorization scheme imposed by the Oxford Centre for Evidence-based Medicine (Oxford Centre for Evidence-based Medicine, 2009). 


\section{Materials and Methods}

The study was conducted in accordance with the ethical approval from the IRB (IRB meeting number 620-73, on the $15^{\text {th }}$ of May 2016). The approval is under the authority of the dean office at the College of Medicine at the University of Baghdad. This study was conducted in a population of undergraduate medical students from Iraq $(\mathrm{n}=195)$. The participants were randomly selected out of a total of 261 medical students. Randomization was based on the selection of three groups A, B, and C $(n=67, n=61, n=67)$ of students out of four groups via using a random number generator (Figure 2). The male-to-female ratio was 3:10 for each cluster (group). The participants were blinded to the nature and outcome of this study, those who were responsible for data collection were also blinded, and only the statistician was not blinded. Hence, this study is considered to be randomised and double-blinded.

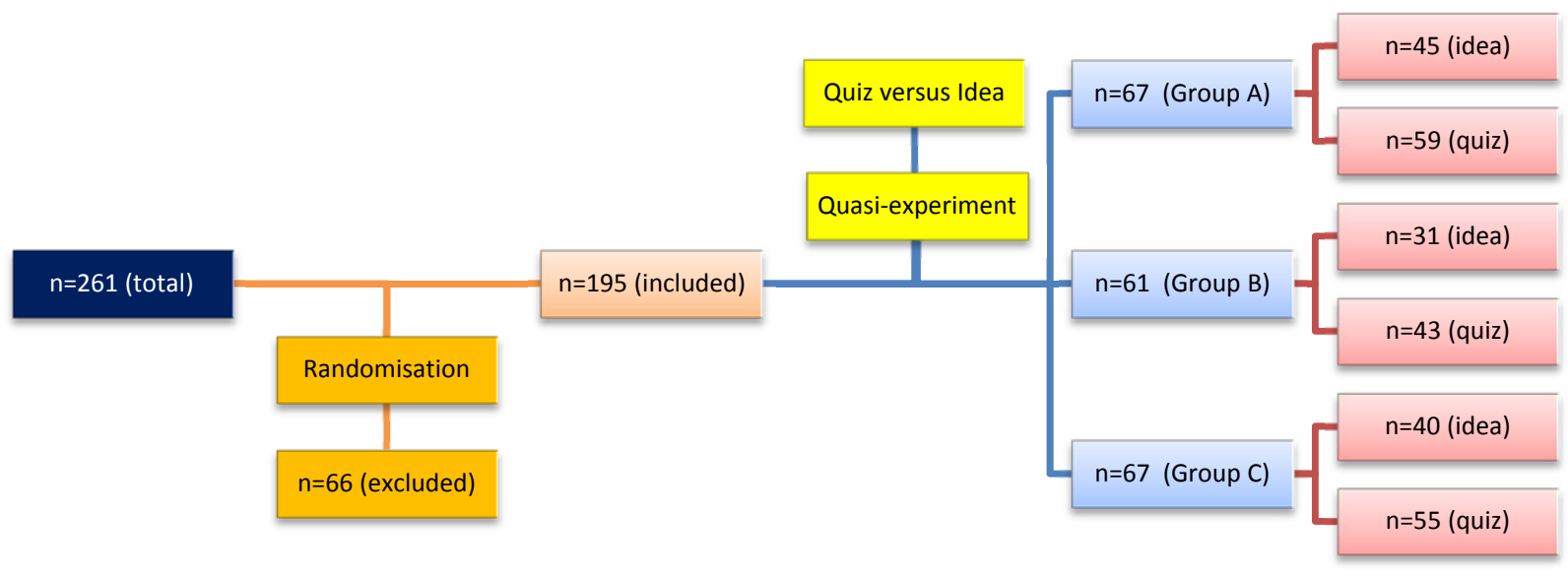

Figure 2. Flow Chart: Design of the Study

Each of the three groups was interviewed separately and were given the option to either answer a classic quiz or to write down an idea/question with creative potential(s) or to carry out both. The quiz was the same for all participants and for all the three groups; the topic of the quiz was already taught to the participants (students) in the human Anatomy module of head and neck; it was specifically in connection with the subject of the infrahyoid muscles. On the other hand, the creative idea could be written on any subject, medical or non-medical, and can be drafted in English or the native Arabic language. There were no restrictions of any kind; the time was left open for the students to either answer the quiz or write a creative idea or to respond to both. Each potential original idea was later qualitatively examined by a panel of reviewers using thematic analysis to assess the existence of creative and innovative potentials.

The tested hypothesis included the detection of the presence of any sort of tendencies of students toward creative thinking, the presence of inter-group variability in connection with such trends, and the correlation with the gender of the participants. Statistical testing was carried out using the Pearson's Chi-square test for categorical data; an alpha value of 0.05 (95\% confidence interval) was set as the cutoff margin for statistical significance. The statistical analysis was conducted with the Statistical Package for Social Science Version 20 (SPSS V.20) and Microsoft Excel 2016. A pertinent review of the literature was performed from the $3^{\text {rd }}$ of October 2016 to the $23^{\text {rd }}$ of December 2016; this was done systematically across PubMed/Medline, the Cochrane Library, Scopus, Embase, Google Scholar, in addition to the unpublished (grey) literature. A pre-specified list of keywords was based on the medical subject headings (MeSH) indexed on the National Center for Biotechnology Information (NCBI) (National Center for Biotechnology Information, 2016). Manuscripts of prior studies, both observational and experimental, were evaluated via using the CASP critical appraisal tools (Casp-uk.net, 2016). Additionally, the level-of-evidence for each paper was assessed in accordance with the system imposed by the Oxford Centre for Evidence-based Medicine (Oxford Centre for Evidence-based Medicine, 2009).

\section{Results and Discussion}

The three groups (A, B, and C) were comparable in relation to the age, gender, and critical demographic parameters of interest for the participants; the total number of those who participated in the study was $195\left(n_{A}=67\right.$, 
$\mathrm{n}_{\mathrm{B}}=61, \mathrm{n}_{\mathrm{C}}=67$ ), the male-to-female ratio was approximately 3 to 10 for each group; the age of participants was ranging from 18 to 20 years. The total number of students who chose to take the quiz was $157(80.5 \%)$, while those who decided to write down an idea of creative potential were $116(59.5 \%)$. The number of creative ideas (per student) was variable and in the range of 1-6 per student; the topic of ideas was versatile including the medical, paramedical, and non-medical theme of topics, the majority of which belonged to the discipline of neuroscience.

There have been some significant inter-group differences towards taking the quiz ( $p$-value $=0.040$ ) (Figure 3 ). The three groups displayed heterogeneity in relation to their members' tendencies to take the quiz only 43 participants (70.5\%) from group B took the quiz, while only to 59 participants $(88.1 \%)$ from group A and 55 participants from (82.1\%) group $\mathrm{C}$ have taken the quiz. There have been no significant differences in between the groups to write down a creative idea $(p$-value $=0.170)$. Similarly, there was also no significant difference in between the tendencies of males and females to either take the quiz $(\mathrm{p}=0.905)$ or to write down a creative idea $(\mathrm{p}=0.633)$.

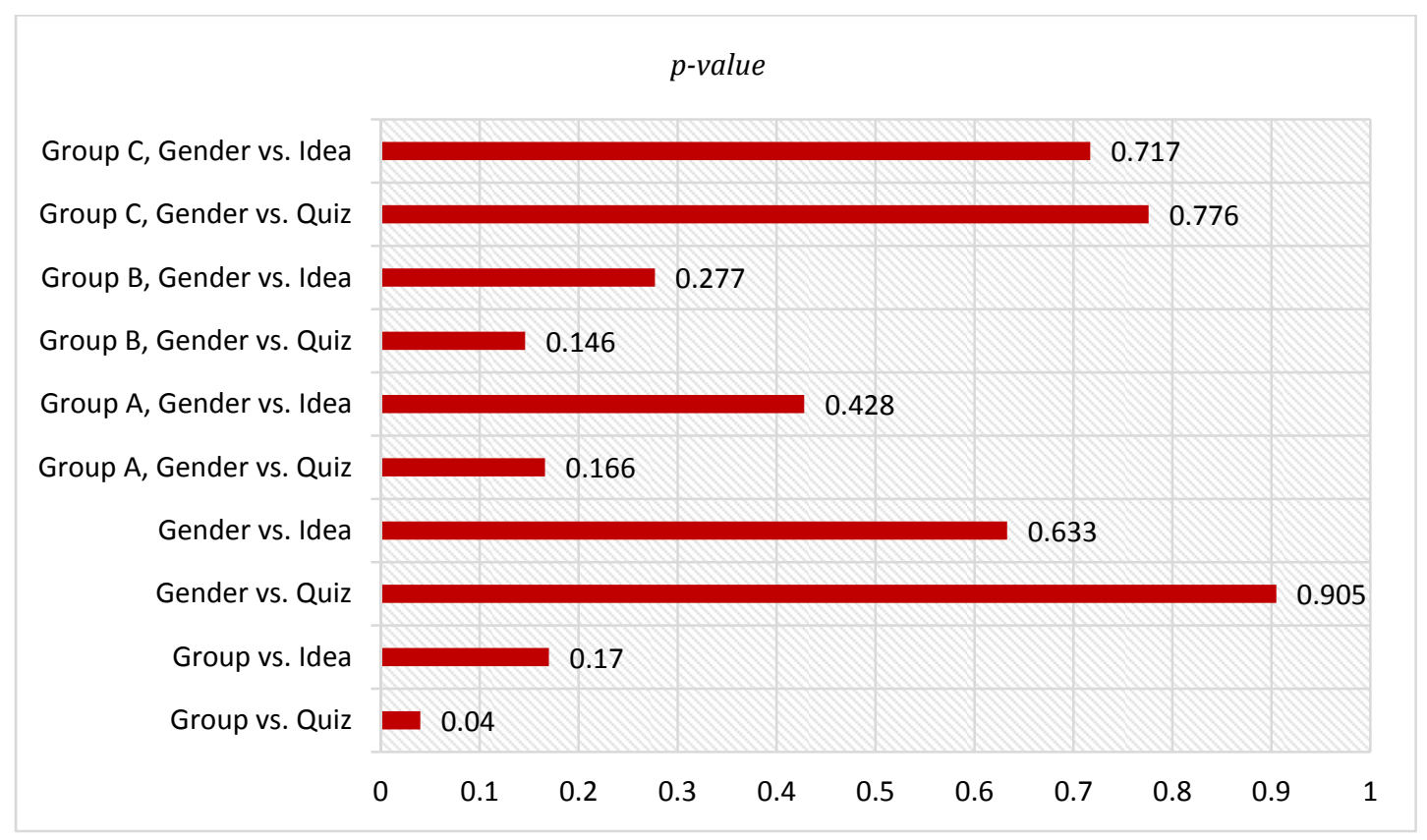

Figure 3. Statistical Inference: $p$-values

Statistical analysis of group A revealed that gender has no role in relation to a student's affinity to either answer the quiz question $(\mathrm{p}=0.166)$ or write down a creative idea $(\mathrm{p}=0.428)$. Similarly, in group $\mathrm{B}$, gender was not a determinant factor, $p$-values were 0.146 (quiz) and 0.277 (idea). Furthermore, in group $\mathrm{C}$, there was no significant difference, based on gender, towards either answering the quiz $(\mathrm{p}=0.776)$ or generating a creative idea $(\mathrm{p}=0.717)$. To summarise, there was some significant difference in between the groups in relation to their tendencies to take the quiz. However, there were no significant inter-group differences in relation to their affinity to come up with (write) a creative idea. Similarly, inter-group statistical analyses displayed the absence of any significant differences in between males and females to either participate in the quiz or to generate ideas of creative and innovative potentials. Finally, the effect of novel psychoactive substances on cognition and creativity deserve intensive exploration in future studies (Al-Imam et al., 2016; Al-Imam et al., 2017, Al-Imam, 2017a; Al-Imam, 2017b).

\section{Conclusion}

The creative and innovative mental abilities of medical students have always been under speculation; these were never tested in Iraqi medical students, neither in undergraduates nor in postgraduates. Besides, the theme and the meaning of creativity itself is ambiguous and not yet properly defined nor been adequately measured. However, this study has succeeded to provide a simple, yet a reliable way to gauge the affinity of medical students toward creative thinking. It was found that there was no evident difference in between the tendencies of medical students to engage in ideas of original content or standard thinking pattern. However, some students who had provided creative ideas generated a significant number of ideas up to six in number on a variety of themes including medical and non-medical, and particularly in relation to the discipline of neuroscience. 
The study has three main limitations; it was conducted in a population of undergraduate medical students, participants from postgraduate levels were excluded (1), the content of written Ideas was assessed for creative potentials by a panel; the panel included the authors of this paper (2), and there has been no assessment of student's handedness in correlation with his (her) affinities towards creative thinking (3). In 2016, Al-Hadithi and colleagues have studied the effect of the patterns of cerebral dominance within a population of Iraqi medical students, and the correlation of those patterns with the visual analytic skills (Al-Hadithi et al., 2016). Future studies should compare the different population of students, medical and non-medical, in addition to the inclusion of postgraduate students.

\section{Acknowledgements}

Recognition and gratitude to the undergraduate medical students of the College of Medicine at the University of Baghdad, for their participation and enthusiasm, to be involved in this study. Our appreciation to Hussein Al-Bayati, a second-year medical student, for his artistic creativity and provision of the concept art (Figure 1) of this manuscript.

\section{Competing Interests Statement}

The authors have nothing to be declared.

\section{Source of Funding}

This study has been entirely self-funded by the authors.

\section{References}

Al-Hadithi, N., Al-Imam, A., Irfan, M., Khalaf, M., \& Al-Khafaji, S. (2016). The relation between cerebral dominance and visual analytic skills in Iraqi medical students, a cross sectional analysis. Asian Journal of Medical Sciences, 7(6), 47-52. https://doi.org/10.3126/ajms.v7i6.15205

Al-Imam, A. (2017a). Could Hallucinogens Induce Permanent Pupillary Changes in (Ab) users? A Case Report from New Zealand. Case Reports in Neurological Medicine, 2017. https://doi.org/10.1155/2017/2503762

Al-Imam, A. (2017b). The relation between cerebral dominance and visual analytic skills in Iraqi Medical students, a cross sectional analysis. Journal of the Anatomical Society of India, 66(1), 42-43. https://doi.org/10.1016/j.jasi.2017.08.136

AL-Imam, A., Santacroce, R., Roman - Urrestarazu, A., Chilcott, R., Bersani, G., Martinotti, G., \& Corazza, O. (2017). Captagon: use and trade in the Middle East. Human Psychopharmacology: Clinical and Experimental, $32(3)$.

Al-Imam, A., Simonato, A. P., \& Corazza, O. (2016). Haloperidol, an old antipsychotic with potential use by NPS users in Iraq. Research and Advances in Psychiatry, 3(3), 81-84. Retrieved from https://www.rapjournal.eu/materiale_cic/948_3_3/8031_haloperidol/article.htm

Allen, A. P., \& Loughnane, L. (2016). Cognition About the Creative Process-Interview With Dr Andrew P. Allen. Europe's journal of psychology, 12(4), 679. https://doi.org/10.5964/ejop.v12i4.1323

Amir, O., \& Biederman, I. (2016). The Neural Correlates of Humor Creativity. Frontiers in human neuroscience, 10. https://doi.org/10.3389/fnhum.2016.00597

Bayley, N. (1957). Data on the growth of intelligence between 16 and 21 years as measured by the Wechsler-Bellevue Scale. The Journal of genetic psychology, 90(1), 3-15. https://doi.org/10.1080/00221325.1957.10532997

Bendetowicz, D., Urbanski, M., Aichelburg, C., Levy, R., \& Volle, E. (2017). Brain morphometry predicts individual creative potential and the ability to combine remote ideas. Cortex, 86, 216-229. https://doi.org/10.1016/j.cortex.2016.10.021

Bossomaier, T., Harré, M., Knittel, A., \& Snyder, A. (2009). A semantic network approach to the creativity quotient (CQ). Creativity Research Journal, 21(1), 64-71. https://doi.org/10.1080/10400410802633517

Casp-uk.net. Critical Appraisal Skills Programme (CASP). Retrieved 15 September 2016, from http://www.casp-uk.net/

Furnham, A., Batey, M., Anand, K., \& Manfield, J. (2008). Personality, hypomania, intelligence and creativity. Personality and Individual Differences, 44(5), 1060-1069. https://doi.org/10.1016/j.paid.2007.10.035

Guertin, W. H., Ladd, C. E., Frank, G. H., Rabin, A. I., \& Hiester, D. S. (1966). Research with the Wechsler Intelligence Scales for Adults. Psychological Bulletin, 66(5), 385. https://doi.org/10.1037/h0020410 
Guertin, W. H., Rabin, A. I., Frank, G. H., \& Ladd, C. E. (1962). Research with the Wechsler Intelligence Scales for Adults: 1955-60. Psychological Bulletin, 59(1), 1. https://doi.org/10.1037/h0040560

Kleibeuker, S. W., Stevenson, C. E., van der Aar, L., Overgaauw, S., van Duijvenvoorde, A. C., \& Crone, E. A. (2017). Training in the adolescent brain: An fMRI training study on divergent thinking. Developmental psychology, 53(2), 353. https://doi.org/10.1037/dev0000239

National Center for Biotechnology Information. MeSH. Retrieved 16 December 2016, from https://www.ncbi.nlm.nih.gov/mesh/

Oscoz-Irurozqui, M., \& Ortuño, F. (2016). Geniuses of medical science: Friendly, open and responsible, not mad. Medical hypotheses, 97, 71-73. https://doi.org/10.1016/j.mehy.2016.10.020

Oxford Centre for Evidence-based Medicine. Levels of Evidence (March 2009). Retrieved 3 September 2016, from http://www.cebm.net/oxford-centre-evidence-based-medicine-levels-evidence-march-2009/

Piffer, D. (2012). Can creativity be measured? An attempt to clarify the notion of creativity and general directions for future research. Thinking Skills and Creativity, 7(3), 258-264. https://doi.org/10.1016/j.tsc.2012.04.009

Romey, W. D. (1970). What is your creativity quotient?. School Science and Mathematics, 70(1), 3-8. https://doi.org/10.1111/j.1949-8594.1970.tb08557.x

Seashore, H., Wesman, A., \& Doppelt, J. (1950). The standardization of the Wechsler intelligence scale for children. Journal of Consulting Psychology, 14(2), 99. https://doi.org/10.1037/h0056307

Snyder, A., Mitchell, J., Bossomaier, T., \& Pallier, G. (2004). The creativity quotient: an objective scoring of

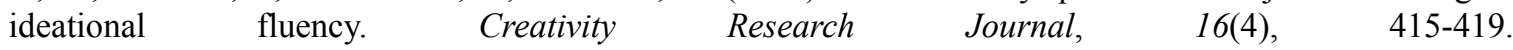
https://doi.org/10.1080/10400410409534552

\section{Copyrights}

Copyright for this article is retained by the author(s), with first publication rights granted to the journal.

This is an open-access article distributed under the terms and conditions of the Creative Commons Attribution license (http://creativecommons.org/licenses/by/4.0/). 